\title{
OS SEMINARIOS PAT DA FACULTADE DE ECONOMÍA E EMPRESA NA NOVA NORMALIDADE ACADÉMICA
}

\author{
Rodríguez-Gulías, María Jesús ${ }^{1}$ \\ ${ }^{1}$ Universidade da Coruña , \\ Facultade de Economía e Empresa, \\ ORCID 0000-0001-8390-474X
}

\section{RESUMO}

0 Plan de Acción Titorial (PAT) da Facultade de Economía e Empresa (FEE) da Universidade da Coruña (UDC) tivo que enfrontarse no curso 2020-2021, como o resto da Universidade, á Nova Normalidade Académica (NNA) derivada da crise sanitaria provocada polo virus SARS-CoV-2 que deu lugar á enfermidade COVID-19. Un dos aspectos nos que o PAT da FEE debeu adaptarse á NNA foi no relativo ao seu Plan de Formación coordinado dende o Servizo de Formación do PAT e no que se encadran os Seminarios PAT da FEE, cursos breves de formación complementaria, transversal, opcional e gratuíta. Coa intención de manter en funcionamento o Servizo de Formación do PAT e continuar ofertando os Seminarios PAT da FEE, decidiuse facer un movemento cara a un sistema de seminarios PAT virtuais e síncronos a través da plataforma MS TEAMS, así como a unha coordinación e xestión dos mesmos tamén maioritariamente telemática. Os resultados deste necesario cambio de sistema foron positivos e, non so se mantiveron os seminarios que tradicionalmente se viñan impartindo, se non que incluso se incrementou a oferta dos mesmos, logrando cifras de asistencia notables.

PALABRAS CLAVE: Plan de Acción Titorial, seminarios, formación en liña, Nova Normalidade Académica. 


\section{CITA RECOMENDADA:}

Rodríguez Gulías, María Jesús (2021): Os Seminarios PAT da Facultade de Economía e Empresa na Nova Normalidade Académica. En García Naya, J.A. (ed.) (2021). Contextos universitarios transformadores: a nova normalidade académica. Leccións aprendidas e retos de futuro. $V$ Xornadas de Innovación Docente. Cufie. Universidade da Coruña. A Coruña (pág. 315-323).

DOl capítulo: https://doi.org/10.17979/spudc.9788497498180.315

DOl libro: https://doi.org/10.17979/spudc.9788497498180

\section{ABSTRACT}

The Tutorial Action Plan (PAT) of the Facultade de Economía e Empresa (FEE) of the Universidade da Coruña (UDC) had to face in the academic year 2020-2021, like the rest of the University, with the New Academic Normal (NAN) arising from the health crisis caused by the SARS-CoV-2 virus that gave rise to COVID-19 disease. One of the aspects in which the FEE PAT had to adapt to the NAN was in relation to its Coordinating Training Plan from the PAT Training Service and in which the FEE PAT Seminars are framed, short courses of complementary, transversal, optional and free training. With the aim of keeping the PAT Training Service running and continuing to offer the FEE PAT Seminars, it was decided to make a move towards a system of virtual and synchronous PAT seminars through the MS TEAMS platform, as well as a mostly telematic coordination and management. The results of this necessary change of system have been positive and, not only have the Seminars traditionally taught been maintained, but also the offer has been increased, achieving remarkable attendance figures.

KEY WORDS: Tutorial Action Plan, seminars, online formation, new academic normal.

\section{AGRADECEMENTO}

0 cambio de sistema a un modelo virtual dos Seminarios PAT da FEE non sería posible sen a colaboración e boa disposición de tódolos/as colaboradores/as de formación do PAT. Grazas. 


\section{INTRODUCIÓN}

A Facultade de Economía e Empresa (FEE) da Universidade da Coruña (UDC) ten como finalidade a formación superior e a investigación nas áreas de Economía e Empresa. Tanto a nivel de estudos de grao como de mestrado, a FEE conta cunha ampla oferta de titulacións. En concreto, para 0 curso 2020-21, as titulacións ofertadas foron as mostradas na Figura 1.
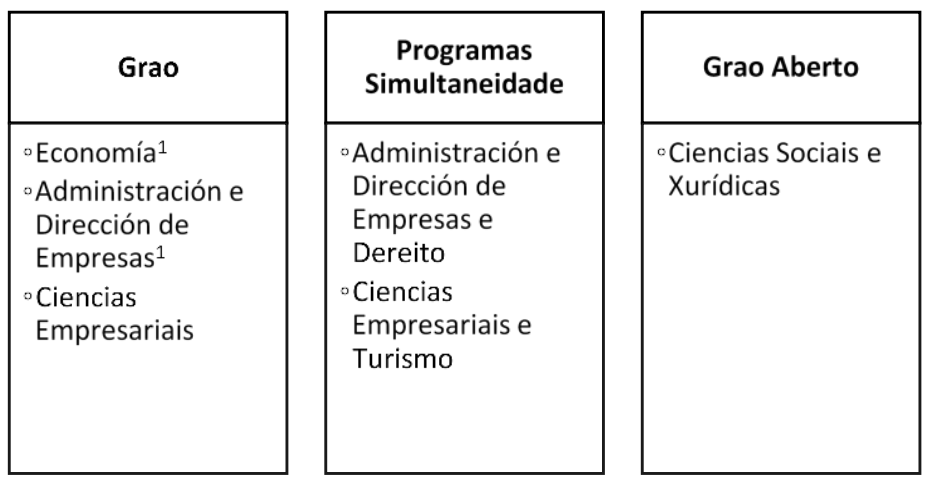

\begin{tabular}{|l|}
\hline Mestrados oficiais \\
\hline -Banca e Finanzas \\
- Contabilidade \\
Superior e \\
Auditoría de \\
Contas \\
- Dirección e \\
Administración de \\
Empresas \\
'Economía \\
\hline
\end{tabular}

Notas: ${ }^{1}$ Titulación que conta con un grupo bilingüe inglés.

Figura 1. Titulacións ofertadas na FEE. Curso 2020-21. Fonte: Universidade da Coruña (2020)

Dita extensa oferta de titulacións implica un número elevado tanto de alumnado coma de profesorado. Os datos de alumnado e profesorado para o curso 2020-21 recóllense na Figura 2.

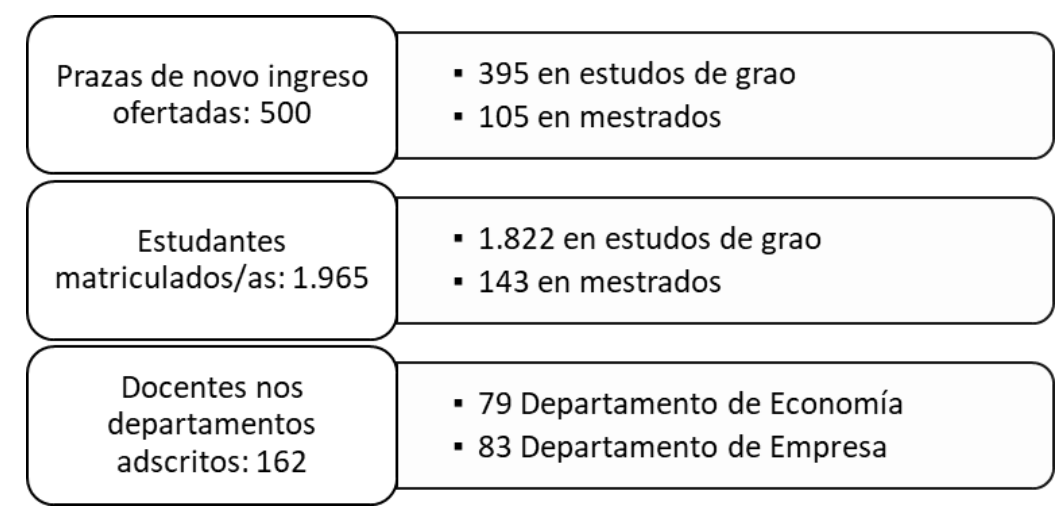

Figura 2. Cifras de alumnado e profesorado na FEE. Curso 2020-21. Fonte: Universidade da Coruña (2020) 
A FEE participa dende máis de hai dez anos no Plan de Acción Titorial (PAT) da UDC coordinado pola Vicerreitoría de Planificación Académica e Innovación Docente. A meta principal do PAT é que o alumnado se sinta acollido na universidade dende o día no que inicia os seus estudos e que poida facer uso dos diferentes servizos e posibilidades que a UDC ofrece.

Un dos principais obxectivos recollidos no Proxecto de PAT da FEE (Universidade da Coruña, 2020) é:

"Ofertar formación complementaria, transversal, opcional e gratuíta a través do Servizo de Formación e Recursos do PAT (SFR-PAT). A oferta realizada dende SFR.FEE tenta dar resposta ás necesidades do alumnado naquelas aptitudes, materias e ferramentas de carácter transversal útiles para o desenvolvemento da profesión, complementando a oferta formativa oficial dos Graos impartidos na propia Facultade."

Trátase dos coñecidos coma Seminarios PAT da FEE, que se veñen realizando dende os comezos do PAT no centro. Neste sentido, o recurso fundamental son os/as Colaboradores/as do Servizo de Formación do PAT. Maioritariamente trátase de profesorado e outro persoal do centro, aínda que tamén participan algúns outros colaboradores/as externos ao centro e incluso á universidade. Todos/as eles/as participan de xeito voluntario ofrecendo cursos e material formativo.

No curso 2020-2021, a situación derivada da crise sanitaria provocada pola COVID fixo preciso repensar o sistema de Seminarios PAT que tan ben viña funcionando nos cursos previos. Por unha banda, as limitacións en canto a aforo fixeron que os espazos dispoñibles no centro se visen reducidos. Por outra banda, tampouco parecía convinte ou prudente mesturar, nos Seminarios PAT, a alumnado de diferentes titulacións e cursos que, doutro xeito, non terían motivo para entrar en contacto. Por iso, se decidiu apostar por un sistema de Seminarios PAT virtuais e síncronos a través da plataforma TEAMS de Microsoft. 
0 obxectivo que se pretendeu lograr con este cambio de sistema foi manter en funcionamento o Servizo de Formación do PAT adaptando o Plan de Formación do PAT da FEE para 0 curso 2020-2021 á Nova Normalidade Académica (NNA).

Despois desta introdución, recollese a descrición da experiencia no segundo epígrafe, seguida dos principais resultados da mesma no terceiro epígrafe. Finalmente, extráense unha serie de conclusións a partir da experiencia desenvolvida e os seus resultados no epígrafe cuarto.

\section{DESCRICIÓN DA EXPERIENCIA}

A novidade principal deste curso académico é, non so o paso de tódolos seminarios ao formato virtual, se non a realización da coordinación e xestión dos mesmos de xeito maioritariamente telemático.

As actividades organizativas desenvolvidas polo Servizo de Formación do PAT no curso 20202021 veñen recollidas na Táboa 1 e detalladas posteriormente.

\begin{tabular}{|c|c|}
\hline ACTIVIDADE & DATAS \\
\hline \multicolumn{2}{|c|}{$1^{0}$ CUADRIMESTRE } \\
\hline Deseño de actividades de formación & De setembro a outubro 2020 \\
\hline Captación de formadores & De setembro a outubro 2020 \\
\hline Publicación e difusión & Outubro 2020 \\
\hline Xestión de inscricións & De outubro a decembro 2020 \\
\hline Desenvolvemento de actividades de formación & De outubro a decembro 2020 \\
\hline Emisión de certificados de impartición & Xaneiro 2021 \\
\hline Emisión de certificados de asistencia & Xaneiro 2021 \\
\hline \multicolumn{2}{|c|}{$2^{\circ}$ CUADRIMESTRE } \\
\hline Deseño de actividades de formación & De xaneiro a febreiro 2021 \\
\hline Captación de formadores & De xaneiro a febreiro 2021 \\
\hline Publicación e difusión & Febreiro 2021 \\
\hline Xestión de inscricións & De febreiro a xuño 2021 \\
\hline Desenvolvemento de actividades de formación & De febreiro a xuño 2021 \\
\hline Emisión de certificados de impartición & Xullo 2021 \\
\hline Emisión de certificados de asistencia & Xullo 2021 \\
\hline
\end{tabular}

Táboa 1. Cronograma actividades de formación do PAT da FEE. Curso 2020-21.

Fonte: Adaptado de Universidade da Coruña (2020) 
Ao inicio de cada un dos cuadrimestres, en outubro do 2020 e en febreiro do 2021 (Táboa 1), deséñanse os seminarios PAT que se van a impartir nos mesmos e cáptanse os/as formadores/as que se encargaran de impartilos. Boa parte dos seminarios veñen impartíndose dende fai anos e outros son novas incorporacións que se van engadindo, en ocasións por necesidades que xorden do alumnado e en outras ocasións a proposta do profesorado ou da coordinación do PAT. Os contactos co profesorado realizáronse practicamente na súa totalidade de xeito non presencial, empregando as ferramentas de correo electrónico e videochamadas de MS TEAMS.

0 groso da publicación e difusión dos Seminarios PAT da FEE realizouse, unha vez definidos estes, en outubro do 2020 e en febreiro do 2021, para o primeiro e o segundo cuadrimestre respectivamente (Táboa 1). 0 listado de seminarios PAT publicouse en ditas datas na sección do PAT e na sección de novas da web da FEE. Nel incluíase o título do seminario, o nome do/a docente encargado de impartilo, as datas e horarios de celebración, a duración, así como 0 prazo e o enlace para a inscrición. No momento da publicación dos listados na web do centro, enviouse tamén un correo electrónico a listaxe de distribución do alumnado da Facultade informado da publicación dos mesmos e proxectouse a información nas pantallas da entrada da Facultade. Tamén se deu difusión na conta de Instagram do PAT. A única acción, poderíase dicir que, física foi que se colgaron carteis en papel nos taboleiros informativos do centro.

Adicionalmente, continuouse coa difusión ao longo dos cuadrimestres, toda ela virtual, enviando correos electrónicos recordatorios conforme se aproximaban as datas de finalización dos prazos de inscrición para cada un dos seminarios, información que tamén se compartiu no Instagram.

A xestións das inscricións aos diferentes seminarios realizouse de xeito totalmente telemático mediante a aplicación FORMS de Microsoft. 0 alumnado, coas súas claves de acceso da Universidade, pode acceder e cumprimentar os formularios de inscrición. Recóllense datos persoais que van a permitir emitir os correspondentes certificados de asistencia e outra información de interese como a titulación que cursa a persoa que se inscribe e o seu curso. 
A partir das listaxes de inscritos/as créanse, dende a coordinación do PAT, os eventos formativos na plataforma TEAMS de Microsoft. 0 alumnado inscrito e o profesorado da sesión reciben por correo electrónico a invitación á sesión formativa. Na invitación á sesión danse as indicacións oportunas para acceder á mesma. En paralelo, dáse permisos aos docentes para que poidan presentar e compartir pantalla e infórmaselles do número de persoas inscritas e 0 perfil das mesmas.

No momento da realización do seminario a coordinadora PAT adoita presentar aos poñentes e moderar á sesión, resolvendo as incidencias que poden xurdir (problemas de acceso, dificultades para presentar, etc.). Finalizada a mesma, descarga o listado de asistentes.

Rematados os seminarios PAT de cada cuadrimestre emítense os certificados de asistencia para o alumnado e os correspondentes fai constar para o profesorado que impartiu os mesmos. Todos estes documentos se entregan por correo electrónico asinados dixitalmente mendiante a plataforma Portafirmas da UDC en formato electrónico PDF.

\section{RESULTADOS}

En canto aos resultados da experiencia do paso a virtual da totalidade dos Seminarios do Plan de Formación do PAT da FEE, a Táboa 2 recolle os seminarios impartidos, así coma o número de alumnos/as que asistiron a cada un deles. 


\begin{tabular}{|c|c|}
\hline TÍTULO DO SEMINARIO & N. ${ }^{0}$ \\
\hline \multicolumn{2}{|l|}{$1^{\circ}$ CUADRIMESTRE } \\
\hline INTRODUCIÓN ÁS FERRAMENTAS DE TELEFORMACIÓN DA UDC ${ }^{a}$ & 8 \\
\hline IGUALDADE DE XÉNERO NA UDC ${ }^{a}$ & 9 \\
\hline ESTUDAR MASTERS E DOUTORAMENTO NO ESTRANXEIRO & 31 \\
\hline INTRODUCCIÓN AO EXCEL PARA ESTATÍSTICA & 38 \\
\hline PRESENTACIÓN DO TFGa & 33 \\
\hline PREPARACIÓN DO TFG (10 edición) & $161^{\mathrm{b}}$ \\
\hline PREPARACIÓN DO TFG ( $2^{0}$ edición) & $67^{\mathrm{b}}$ \\
\hline \multicolumn{2}{|l|}{$2^{\circ}$ CUADRIMESTRE } \\
\hline INTRODUCIÓN Á ANÁLISE DE DATOS CON R & 15 \\
\hline COMO FACER UN CURRÍCULUM & 50 \\
\hline INTRODUCIÓN AO EXCEL PARA FINANZAS & 47 \\
\hline EN BUSCA DA MARXE PERDIDA ${ }^{\mathrm{a}}$ & 37 \\
\hline PREPARACIÓN DO TFG ( $3^{\circ}$ ed.) & $74^{\mathrm{b}}$ \\
\hline GREEN FEE + ELECTROCICLAXE ${ }^{\mathrm{a}}$ & 10 \\
\hline LINKEDIN E REDES PROFESIONAIS ${ }^{\mathrm{a}}$ & 17 \\
\hline PREPARACIÓN EFICIENTE DUNHA ENTREVISTA DE TRABALLOa ${ }^{a}$ & 30 \\
\hline MAQUETACIÓN EN MS WORD DO TFGa & 39 \\
\hline CINE-DEBATE: A VERDADEIRA HISTORIA DO MAGO DE $0 Z$ & 3 \\
\hline REXENERA: META ZERO WASTE, SOSTIBILIDADE E ALIMENTACIÓN KM0a & 16 \\
\hline MÉTODO GTD, TRACKEAR O TEMPO, XESTIONAR TAREFAS E MÁIS ${ }^{\mathrm{a}}$ & 14 \\
\hline SEMINARIO DE COMUNICACIÓN (Pitch + Pecha Kucha) ${ }^{a}$ & 5 \\
\hline ELABORACIÓN DE INFORMES CON DATOS E ELEMENTOS GRÁFICOS EN LIBREOFFICE & 7 \\
\hline COMO ASINAR DOCUMENTOS NA ERA DIXITAL: 0 CERTIFICADO DIXITAL E 0 DNIe ${ }^{\mathrm{a}}$ & 12 \\
\hline $\begin{array}{l}\text { EXPERIENCIA NUN ENTORNO DE PROGRAMACIÓN (R) DUN GRADUADO EN ECONOMÍA DA } \\
\text { FEE }^{\mathrm{a}}\end{array}$ & 12 \\
\hline PRESENTACIÓN ORAL DO TFG ( $\left.2^{\mathrm{a}} \mathrm{ed}.\right)^{\mathrm{a}}$ & 28 \\
\hline PRESENTACIÓN ORAL DO TFG (3a ed. $)^{\mathrm{a}}$ & 10 \\
\hline
\end{tabular}

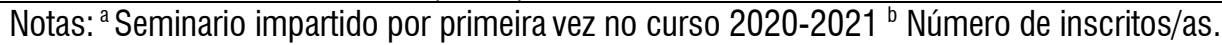

Táboa 2. Seminarios impartidos e número de asistentes. Curso 2020-21. Fonte: Elaboración propia a partir de rexistros de asistencia de TEAMS

Como é posible observar na Táboa 2, en suma ofertáronse un total de 25 Seminarios PAT no curso 2020-2021, impartíndose 7 deles no primeiro cuadrimestre e 18 deles no segundo cuadrimestre, respectivamente. Deles 15 son seminarios impartidos por primeira vez no curso 2020-2021.

En total, houbo entorno a 773 asistentes aos seminarios ofertados polo PAT da FEE ${ }^{20}$ (Táboa 2).

20 Nótese que algunhas persoas asistiron a varios Seminarios PAT e polo tanto é preciso tomar este dato con cautela. 


\section{CONCLUSIÓNS}

A NNA resultado da crise sanitaria provocada pola COVID afectou non só as titulacións oficias de Grao e de Mestrado impartidas na UDC, se non que tivo tamén os seus efectos noutras actividades docentes da Universidade. En particular, neste traballo, tratouse a problemática dos Seminarios PAT da FEE e a súa adaptación á NNA.

Como se comentou previamente, co obxectivo de manter en funcionamento o Servizo de Formación do PAT na situación de NNA coa que se presentaba 0 curso 2020-2021, dende 0 PAT da FEE fíxose unha importante aposta por un sistema de seminarios PAT virtuais e síncronos a través da plataforma MS TEAMS.

Vistos os resultados, consideramos que 0 traslado ao formato virtual dos Seminarios PAT da FEE e da súa xestión acadou os obxectivos propostos e incluso os superou ao ofertar un número de seminarios máis amplo que en cursos previos.

No camiño foi preciso afrontar diversas dificultades, principalmente técnicas, pero o proceso permitiu desenvolver un sistema de traballo que día a día vai sendo máis eficiente.

Nos próximos cursos académicos sería desexable poder aproveitar todo o coñecemento xerado neste curso de NNA e ofrecer unha combinación de seminarios en modalidade presencial, virtual e híbrida.

\section{REFERENCIAS}

Universidade da Coruña (2020). Plan de Acción Titorial da Facultade de Economía e Empresa. https://www.udc.es/export/sites/udc/cufie/_galeria_down/PAT/2020_21/F.-Economiae-Empresa_Proxecto_2020_2021.pdf_2063069294.pdf 
